\title{
Effects of variations in the proportions of saturated, monounsaturated and polyunsaturated fatty acids in the rat diet on spleen lymphocyte functions
}

\author{
BY NICOLA M. JEFFERY ${ }^{1}$, MARIO CORTINA ${ }^{2}$, ERIC A. NEWSHOLME ${ }^{1}$ \\ AND PHILIP C. CALDER ${ }^{1 *}$ \\ Departments of ${ }^{1}$ Biochemistry and ${ }^{2}$ Statistics, University of Oxford, South Parks Road, \\ Oxford OX1 $3 Q U$
}

(Received 2 July 1996 - Revised 3 September 1996 - Accepted 9 September 1996)

\begin{abstract}
To obtain further information about the immunomodulatory effects of specific dietary fatty acids, weanling male rats were fed for 6 weeks on high-fat $(178 \mathrm{~g} / \mathrm{kg})$ diets which differed according to the principal fatty acids present. The nine diets used differed in their contents of palmitic, oleic, linoleic and $\alpha$-linolenic acids; as a result the total polyunsaturated fatty acid (PUFA) content and the PUFA : saturated fatty acid ratio varied (from 17.8 to $58.5 \mathrm{~g} / 100 \mathrm{~g}$ fatty acids and from 0.28 to 5.56 respectively). The $n-6$ PUFA : $n-3$ PUFA ratio was kept constant in all diets at approximately 7.0. The fatty acid compositions of the serum and of spleen lymphocytes were significantly influenced by that of the diet fed. The ex vivo proliferation of spleen lymphocytes decreased as the level of oleic acid in the diet increased. Spleen natural killer cell activity decreased as the oleic acid content of the diet increased and increased as the palmitic acid content of the diet increased. The extent of the effects of these fatty acids on lymphocyte functions was modified by the nature of the background fatty acid composition of the diet.
\end{abstract}

Fatty acids: Dietary lipids: Lymphocytes: Natural killer cell

An effect of dietary fatty acids on the immune system was suggested by early epidemiological studies of the incidence of multiple sclerosis (Swank, 1950) and by the observations that the blood, cells and tissues of patients with multiple sclerosis are deficient in longchain polyunsaturated fatty acids (PUFA) (see Mertin \& Meade, 1977 for references). This suggestion was supported by the observations of Mertin and co-workers who showed that linoleic $(18: 2 n-6)$ and arachidonic $(20: 4 n-6)$ acids inhibit mitogen-stimulated proliferation of human peripheral blood lymphocytes in culture (Mertin et al. 1974) and that subcutaneous injections of these fatty acids prolong the survival of skin allografts in mice (Mertin \& Hunt, 1976). These studies focused on the $n-6$ family of PUFA, but more recently there has been intense interest in the effects of the $n-3$ PUFA. An immunomodulatory effect of these latter fatty acids is suggested by epidemiological studies which show that populations such as Greenland Eskimos, who consume large quantities of fish oils which are rich in the $n$-3 PUFA eicosapentaenoic $(20: 5 n-3)$ and docosahexaenoic $(22: 6 n-3)$ acids, have a very low incidence of inflammatory and autoimmune disorders (Kromann \& Green, 1980). Furthermore, a number of clinical studies have reported that fish oil supplementation has some beneficial effects in acute inflammatory conditions (Grimminger et al. 1993), rheumatoid arthritis (Sperling et al. 1987; Cleland et al. 1988;

\footnotetext{
* For reprints. Present address: School of Biological Sciences, University of Southampton, Bassett Crescent East, Southampton SO16 7PX.
} 
Kremer et al. 1990), multiple sclerosis (Bates et al. 1989; Gallai et al. 1993), psoriasis (Ziboh et al. 1986; Bittiner et al. 1988) and lupus (Das, 1994) and prolongs the survival of grafts (Homan van der Heide et al. 1993). The potential clinical use of oils rich in $n-6$ or $n-3$ PUFA has given rise to a number of investigations of the effects of fatty acids and dietary oils on immune cell functions.

In vitro studies have shown that PUFA, or triacylglycerols (TAG) containing PUFA, inhibit a number of lymphocyte functions including proliferation (Calder et al. 1991, 1992, 1994b; Calder \& Newsholme 1992a,b; Kumar et al. 1992; Soyland et al. 1993), interleukin-2 production (Calder \& Newsholme 1992a,b; Kumar et al. 1992), natural killer (NK) cell activity (Yamashita et al. 1991) and antigen presentation (Fujikawa $e t$ al. 1992). Comparisons between the activities of different fatty acids indicate that eicosapentaenoic acid has the most potent inhibitory action in vitro (see Calder 1995, 1996a,b for reviews). These studies indicate that consumption of PUFA, particularly $n$ - 3 PUFA, in the diet might suppress lymphocyte functions and thus the immune response.

A number of studies have shown that feeding laboratory animals (rats, mice, rabbits, chickens) on diets rich in $n-3$ PUFA (rapeseed, linseed, fish oils; the former two oils contain $\alpha$-linolenic acid $(18: 3 n-3))$ results in suppressed ex vivo lymphocyte proliferation (Marshall \& Johnston, 1985; Kelley et al. 1988; Fritsche et al. 1991; Yaqoob et al. 1994a; Calder et al. 1995; Yaqoob \& Calder, 1995; Jeffery et al. 1996a), cytotoxic T-lymphocyte activity (Erickson, 1984; Olson et al. 1987; Fritsche \& Johnston, 1989, 1990; Fritsche \& Cassity, 1992) and NK cell activity (Meydani et al. 1988; Fritsche \& Johnston, 1990; Berger et al. 1993; Yaqoob et al. 1994b; Jeffery et al. 1996a); investigations which have directly compared the effects of these oils indicate that fish oil is more suppressive than linseed oil which is, in turn, more suppressive than rapeseed oil. Diets rich in $n-6$ PUFA are less suppressive than those containing $n-3$ PUFA or without effect (e.g. Yaqoob et al. 1994a; Jeffery et al. 1996a). Taken together these ex vivo observations indicate that consumption of diets containing $n-3$ PUFA, particularly diets rich in fish oil, may result in immunosuppression in vivo. Indeed, it has been reported that feeding laboratory rodents fish or linseed oil results in diminished in vivo graft $v$. host and/or host $v$. graft responses (Mertin et al. 1985; Hinds \& Sanders, 1993; Sanderson et al. 1995a; Jeffery et al. 1996a); feeding diets rich in $n-6$ PUFA did not suppress these responses (Sanderson et al. 1995a).

Thus, the study of the effects of consumption of diets rich in $n-3$ or $n-6$ PUFA has received a great amount of attention; the effects of other dietary oils have been little studied. However, recent investigations have revealed that feeding laboratory rodents on diets very rich in oleic acid $(18: 1 n-9)$ also results in significant suppression of lymphocyte responses ex vivo (Yaqoob et al. 1994a,b; Jeffery et al. 1996b) and in the host $v$. graft response in vivo (Sanderson et al. 1995a), suggesting that oleic acid has an immunomodulatory action.

The studies outlined here have used large amounts of a single oil, or of mixtures of two oils, in the diet of laboratory rodents. As such, they represent the pharmacological use of dietary fatty acids, which is clearly relevant to various clinical situations. However such extreme diets are unlikely to be encountered by free-living human beings. Furthermore, the use of such oils inevitably results in variation in the levels of several fatty acids other than those under investigation. It seems important to investigate the effects of relatively small changes in the levels of the commonly consumed fatty acids in a controlled manner in which one fatty acid is exchanged for another without altering the levels of the other fatty acids in the diet. Therefore in the current study we fed weanling rats on one of nine diets, each containing $178 \mathrm{~g}$ fat $/ \mathrm{kg}$, but differing in the proportions of palmitic, oleic, linoleic and $\alpha$-linolenic acids; the $n$ - 6 PUFA : $n-3$ PUFA ratio was kept constant at approximately 7 and 
the PUFA : saturated fatty acids ratio (P:S ratio) was varied from 0.28 to 5.56 . We investigated the effect of these diets on serum fatty acid composition and on spleen lymphocyte fatty acid composition and functions.

\section{MATERIALS AND METHODS}

\section{Animals and diets}

Weanling male Lewis rats (aged 3 weeks, weighing approximately $50 \mathrm{~g}$ ) were obtained from Harlan-Olac, Bicester, Oxon. The animals were housed in the Department of Biochemistry for a period of 6 weeks before slaughter, during which time they were allowed access, ad libitum, to water and to one of nine experimental diets, which were provided by Unilever Research Colworth Laboratory, Sharnbrook, Beds. All diets contained $178 \mathrm{~g}$ lipid $/ \mathrm{kg}$ (Table 1) but they differed according to the proportions of palmitic, oleic, linoleic and $\alpha$-linolenic acids they contained (Table 2). The comparisons being made are summarized in Table 3 . Rats were killed in the fed state by an overdose of $\mathrm{CO}_{2}$. Serum was prepared by allowing blood to clot at room temperature for $1 \mathrm{~h}$ and then centrifuging at $1000 \mathrm{~g}$ for $5 \mathrm{~min}$. Spleen lymphocytes were prepared as described elsewhere (Yaqoob et al. 1994a).

\section{Chemicals}

Chemicals and cell culture medium and supplements were obtained from the sources described elsewhere (Calder et al. 1994a; Yaqoob et al. 1994a,b, 1995b; Sanderson et al. $1995 a$ ).

\section{Lipid extraction and fatty acid composition analysis}

Lipid was extracted from serum or from lymphocytes with chloroform-methanol $(2: 1$, $\mathrm{v} / \mathrm{v}$ ). Fatty acids were prepared by overnight saponification at $70^{\circ}$ in methanolic $0.5 \mathrm{M}-$ $\mathrm{KOH}$. Samples were neutralized using $18 \mathrm{M}-\mathrm{H}_{2} \mathrm{SO}_{4}$ and fatty acids were extracted into

Table 1. Composition of the diets used

\begin{tabular}{lc}
\hline Component & Level in the diet $(\mathrm{g} / \mathrm{kg})$ \\
\hline High-nitrogen casein & 182 \\
Starch & 520 \\
Solkafloc (cellulose) & 60 \\
Mineral mix* & 42 \\
Methionine & 4 \\
Vitamin mix $\dagger$ & 12 \\
Choline bitartrate & 2 \\
Lipid & 178 \\
\hline
\end{tabular}

\footnotetext{
*AIN-76 containing per $\mathrm{kg}$ : calcium phosphate dibasic $500 \mathrm{~g}$, sodium chloride $74 \mathrm{~g}$, potassium citrate monohydrate $220 \mathrm{~g}$, potassium sulfate $52 \mathrm{~g}$, magnesium oxide $24 \mathrm{~g}$, manganese carbonate $3.5 \mathrm{~g}$, ferric citrate $6 \mathrm{~g}$, zinc carbonate $1.6 \mathrm{~g}$, cupric carbonate $0.3 \mathrm{~g}$, potassium iodate $0.01 \mathrm{~g}$, sodium selenite $0.01 \mathrm{~g}$, chromium potassium sulfate $0.55 \mathrm{~g}$, sucrose $118 \mathrm{~g}$.

† Containing per kg: retinyl palmitate $1.8 \mathrm{~g}$, ergocalciferol $0.125 \mathrm{~g}, \mathrm{dl}-\alpha$-tocopherol $22 \mathrm{~g}$, ascorbic acid $45 \mathrm{~g}$, inositol $5 \mathrm{~g}$, choline chloride $75 \mathrm{~g}$, menadione $2.25 \mathrm{~g}, p$-aminobenzoic acid $5 \mathrm{~g}$, niacin $4.25 \mathrm{~g}$, riboflavin $1 \mathrm{~g}$, pyridoxine hydrochloride $1 \mathrm{~g}$, thiamine hydrochloride $1 \mathrm{~g}$, calcium pantothenate $3 \mathrm{~g}$, biotin $0.02 \mathrm{~g}$, pteroylglutamic acid $0.09 \mathrm{~g}$, cyanocobalamin $0.00135 \mathrm{~g}$, carrier glucose $833.46 \mathrm{~g}$.
} 
Table 2. Fatty acid composition of the diets used

\begin{tabular}{|c|c|c|c|c|c|c|c|c|c|c|c|c|}
\hline \multirow[b]{2}{*}{ Diet } & \multicolumn{7}{|c|}{ Fatty acid (g/100 g total fatty acids) } & \multicolumn{3}{|c|}{$\mathrm{g} / 100 \mathrm{~g}$ total fatty acids } & \multirow[b]{2}{*}{$P: S$} & \multirow[b]{2}{*}{$n-6: n-3$} \\
\hline & $14: 0$ & $16: 0$ & $16: 1 n-7$ & $18: 0$ & $18: 1 n-9$ & $18: 2 n-6$ & $18: 3 n-3$ & SFA & MUFA & PUFA & & \\
\hline $\mathbf{A}$ & 0.9 & 56.6 & 0.1 & 5.4 & 18.5 & 15.4 & $2 \cdot 1$ & 62.9 & 18.6 & 17.5 & 0.28 & $7 \cdot 3$ \\
\hline B & 0.6 & 37.9 & 0.1 & 4.9 & 19.8 & 30.9 & 4.4 & 43.4 & 19.9 & $35 \cdot 3$ & 0.81 & $7 \cdot 3$ \\
\hline $\mathrm{C}$ & 0.3 & 21.9 & 0.2 & 4.4 & 19.7 & 45.8 & $6 \cdot 3$ & $26 \cdot 6$ & 19.9 & $52 \cdot 1$ & 1.93 & 7.0 \\
\hline D & 0.1 & $10 \cdot 3$ & 0.2 & 4.2 & $25 \cdot 2$ & 51.7 & 6.8 & 14.6 & 25.7 & 58.5 & 4.01 & 7.6 \\
\hline $\mathbf{E}$ & 0.1 & 6.2 & 0.2 & 3.2 & 35.6 & 46.2 & 6.6 & 9.5 & 35.8 & 52.8 & 5.56 & 7.0 \\
\hline$F$ & 0.3 & 22.4 & 0.1 & 4.5 & 36.8 & $30 \cdot 3$ & 4.2 & 27.2 & 36.9 & 34.5 & 1.27 & 7.2 \\
\hline $\mathbf{G}$ & 0.3 & 22.4 & 0.2 & 4.5 & $53 \cdot 1$ & $15 \cdot 6$ & 2.2 & 27.2 & $53 \cdot 3$ & 17.8 & 0.65 & $7 \cdot 1$ \\
\hline $\mathbf{H}$ & 0.1 & $5 \cdot 2$ & $0-2$ & $3 \cdot 2$ & 53.7 & 30.9 & 4.4 & 8.5 & 53.9 & $35 \cdot 3$ & $4 \cdot 15$ & 7.0 \\
\hline I & ND & 4.5 & 0.2 & 4.0 & 71.6 & 15.4 & 2.2 & 8.5 & 71.8 & 17.6 & 2.07 & 7.0 \\
\hline
\end{tabular}

SFA, saturated fatty acid; MUFA, monounsaturated fatty acid; PUFA, polyunsaturated fatty acid; P:S, PUFA : SFA ratio; $n-6: n-3, n-6$ PUFA : $n-3$ PUFA ratio; ND, not detected.

Table 3. Fatty acid comparisons being made

\begin{tabular}{lll}
\hline \hline Diets being compared & Fatty acid change & Background \\
\hline A, G, I & Palmitic replaced by oleic & Low PUFA \\
B, F, H & Palmitic replaced by oleic & Moderate PUFA \\
C, D, E & Palmitic replaced by oleic & High PUFA \\
A, B, C, D & Palmitic replaced by PUFA & Low oleic \\
F, E & Palmitic replaced by PUFA & Moderate oleic \\
G, H & Palmitic replaced by PUFA & High oleic \\
D, E, H, I & PUFA replaced by oleic & Low palmitic \\
C, F, G & PUFA replaced by oleic & Moderate palmitic \\
\hline \hline
\end{tabular}

PUFA, polyunsaturated fatty acid.

ethyl acetate. After evaporation to dryness, methyl esters of fatty acids were prepared by reaction with an excess of diazomethane in ether. Fatty acid methyl esters (dissolved in methyl acetate) were separated by GC in a Hewlett-Packard 6890 gas chromatograph (Hewlett Packard, Avondale, PA, USA) fitted with a $30 \mathrm{~m} \times 0.32 \mathrm{~mm}$ DB23 capillary column, film thickness $0.25 \mu \mathrm{m} . \mathrm{N}_{2}$ at $2.0 \mathrm{ml} / \mathrm{min}$ was used as the carrier gas and the split/splitless injector was used with a split: splitless ratio of $10: 1$. Injector and detector temperatures were $170^{\circ}$ and $250^{\circ}$ respectively. The column oven temperature was maintained at $170^{\circ}$ for $12 \mathrm{~min}$ after sample injection and was programmed to then increase from 170 to $200^{\circ}$ at $5^{\circ} / \mathrm{min}$ before being maintained at $200^{\circ}$ for $15 \mathrm{~min}$. The separation was recorded with HP GC Chem Station software. Fatty acid methyl esters were identified by comparison with standards run previously.

\section{Lymphocyte proliferation}

Spleen lymphocytes were cultured at $37^{\circ}$ in an air- $\mathrm{CO}_{2}(19: 1, \mathrm{v} / \mathrm{v})$ atmosphere in ninetysix-well micro-titre culture plates at a density of $5 \times 10^{5}$ cells/well and a total culture volume of $200 \mu \mathrm{l}$ in HEPES-buffered RPMI supplemented with $2 \mathrm{mM}$ glutamine, $25 \mathrm{ml}$ autologous serum/1, antibiotics (streptomycin and penicillin) and, for stimulated lymphocytes, $5 \mu \mathrm{g} / \mathrm{ml}$ concanavalin A (Con A). After $48 \mathrm{~h}$ of culture, $\left[6-{ }^{3} \mathrm{H}\right]$ thymidine was added to each well $(7.4 \mathrm{kBq} /$ well $)$ and the cells were incubated for a further $18 \mathrm{~h}$. The 
cells were then harvested onto glass-fibre filters and washed and dried using a Skatron Cell Harvester (Skatron Instruments, Lier, Norway). Radioactive thymidine incorporation was determined by liquid scintillation counting. The results are expressed as a stimulation index:

$$
\text { stimulation index }=\frac{\text { incorporation of }\left[{ }^{3} \mathrm{H}\right] \text { thymidine in the presence of Con } \mathrm{A}}{\text { incorporation of }\left[{ }^{3} \mathrm{H}\right] \text { thymidine in the absence of Con } \mathrm{A}} .
$$

\section{Spleen lymphocyte natural killer cell activity}

Spleen lymphocytes $(100 \mu \mathrm{l})$ suspended in RPMI supplemented with 2 mM-glutamine and YAC-1 cells $\left(2 \times 10^{4}\right.$ cells $\left./ 100 \mu \mathrm{l}\right)$ suspended in RPMI supplemented with $2 \mathrm{mM}$ glutamine and $10 \mathrm{~g}$ bovine serum albumin/1 were added, in triplicate, to each well of a ninety-six-well flat-bottomed micro-titre plate to yield lymphocyte: target cell ratios of $100: 1$ and $50: 1$. Plates were centrifuged at $300 \mathrm{rev} . / \mathrm{min}$ for $3 \mathrm{~min}$ to bring lymphocytes and target cells into contact and were then incubated at $37^{\circ}$ in an air- $\mathrm{CO}_{2}(19: 1, \mathrm{v} / \mathrm{v})$ atmosphere for $4 \mathrm{~h}$. After the incubation, the plates were centrifuged at $500 \mathrm{rev} . / \mathrm{min}$ for $5 \mathrm{~min}$. Target cell killing was determined by release of lactate dehydrogenase (EC 1.1.1.2; $\mathrm{LDH}$ ) into the medium, as measured by a 'cytotoxicity assay kit' purchased from Proteins International Inc., Rochester Hills, MI, USA. Maximal LDH release was determined by incubating YAC-1 cells with $25 \mathrm{ml}$ Triton X-100/1 in RPMI, instead of the lymphocytes. Spontaneous LDH release was determined by incubating YAC-1 cells with glutamine- and antibiotic-supplemented RPMI in place of the lymphocytes. Percentage cytolysis was calculated as:

$$
\% \text { cytolysis }=\frac{\text { experimental LDH release }- \text { spontaneous } \mathrm{LDH} \text { release }}{\text { maximum LDH release }- \text { spontaneous } \mathrm{LDH} \text { release }} \times 100 .
$$

\section{Analysis of lymphocyte subpopulations}

Flow cytometry was used to measure the presence of various markers on the surface of freshly-prepared spleen lymphocytes. Approximately $10^{6}$ cells (resuspended in phosphatebuffered saline supplemented with $1 \mathrm{~g}$ bovine serum albumin/1 and $10 \mathrm{mM}$-sodium azide (modified PBS)) were incubated for $20 \mathrm{~min}$ at $4^{\circ}$ with monoclonal antibodies to CD4 (W3/25) or CD8 (MRC OX-8). Incubation with a monoclonal antibody to the human C3b inactivator protein (MRC OX-21) was used as a negative control. Following staining with monoclonal antibodies, the cells were washed twice with modified PBS and incubated with fluorescein isothiocyanate-labelled rabbit anti-mouse immunoglobulin G (IgG) for 20 min at $4^{\circ}$. They were washed twice with modified PBS and then suspended in formaldehyde in PBS $(20 \mathrm{ml} / 1)$ and examined for fluorescence using a Becton Dickinson FACScan fluorescence-activated cell sorter (Becton Dickinson, Lincoln Park, NJ, USA). Fluorescence data were collected on $10^{4}$ viable cells.

\section{Data presentation and statistical analysis}

Data shown are mean values with their standard errors of three to five animals fed on each diet. Statistical significance between groups was determined using one-way ANOVA followed by a least-significant difference test (performed using SPSS version 6.0; Statistical Package for the Social Sciences Inc., Chicago, IL, USA); a value for $\boldsymbol{P}$ of less than 0.05 was taken to indicate a statistically significant difference. Values for linear 
correlation coefficients ( $r$ ) were determined using the Spearman linear rank correlation test (performed using S-Plus version 3.3 for Windows; Statistical Sciences Inc., Seattle, WA, USA); a value for $P$ of less than 0.05 was taken to indicate a statistically significant correlation. Non-linear and linear modelling of interactions and curve fitting were performed using S-Plus version 3.3.

\section{RESULTS}

\section{Body weight and food intake}

Food intake did not differ among animals fed on the different diets (results not shown). The rate of weight gain was similar in all animals except those fed on diets A or B, which grew at a faster rate (Fig. 1). As a result the final body weight and the total weight gain were significantly higher in animals fed on diets A or B than in those fed on each of the other diets (results not shown). The final body weights and total weight gain were not different among animals fed on the other diets (results not shown). Diets A and B were richest in palmitic acid and contained low proportions of oleic acid (Table 2). There were significant $(P<0.001)$ linear relationships between the palmitic acid content of the diet and animal weight gain $(r 0.896)$ and final body weight $(r 0.861)$. These observations are consistent with our previous observations of greater weight gain and higher final body weight in rats fed on diets rich in saturated fatty acids compared with those fed on diets rich in unsaturated fatty acids (Sherrington et al. 1994; Yaqoob et al. 1995b). It is most likely that the increased weight gain in rats fed on diets containing high proportions of saturated fatty acids was due to an increased deposition of adipose tissue, as we previously observed (Sherrington et al. 1994; Yaqoob et al. 1995b). Indeed, animals fed on diets A or B had larger epididymal fat pads (approximately 3.2 and $2.9 \mathrm{~g}$ respectively) and dorsal wall of abdomen adipose depots (approximately 4.6 and $4.0 \mathrm{~g}$, respectively) than animals fed on the other diets (epididymal fat pad weight $2 \cdot 1-2.6 \mathrm{~g}$; dorsal wall of abdomen adipose depot weight $1.9-3.6 \mathrm{~g})$.

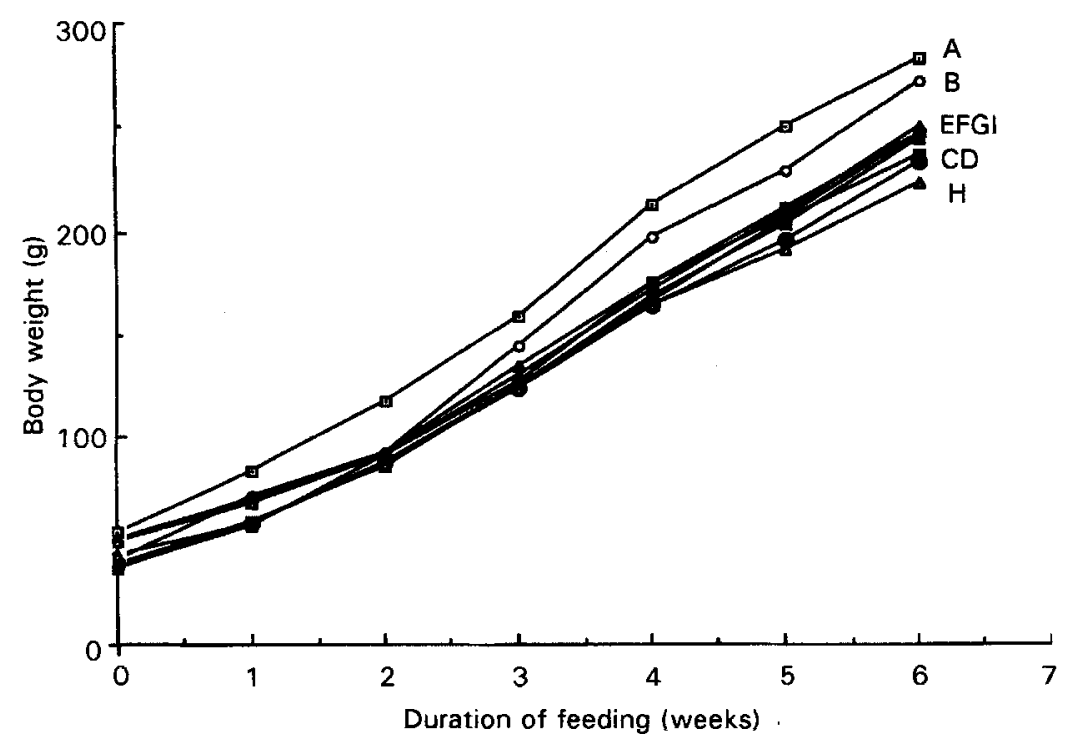

Fig. 1. Weight gain of rats fed on diets with different fatty acid compositions. Letters indicate the diets described in Table 2. Values are means for five animals fed on each diet. 
Table 4. Fatty acid composition of serum from rats fed on diets with different fatty acid compositions*

(Mean values with their standard errors for three or four animals per dietary group)

\begin{tabular}{|c|c|c|c|c|c|c|c|c|c|c|c|c|}
\hline \multirow[b]{3}{*}{ Diet } & \multicolumn{10}{|c|}{ Fatty acid ( $\mathrm{g} / 100 \mathrm{~g}$ total fatty acids) } & & \\
\hline & \multicolumn{2}{|c|}{$16: 0$} & \multicolumn{2}{|c|}{$18: 0$} & \multicolumn{2}{|c|}{$18: 1 n-9$} & \multicolumn{2}{|c|}{$18: 2 n-6$} & \multicolumn{2}{|c|}{$18: 3 n-3$} & \multicolumn{2}{|c|}{$n-6: n-3$ PUFA } \\
\hline & Mean & SE & Mean & SE & Mean & SE & Mean & SE & Mean & SE & Mean & SE \\
\hline A & $43 \cdot 3^{a}$ & 0.9 & $12 \cdot 8^{\mathrm{a}}$ & 0.5 & $16 \cdot 3^{a}$ & 0.4 & $26 \cdot 8^{\mathrm{a}}$ & 0.9 & $0.32^{2}$ & 0.07 & $91 \cdot 6^{2}$ & $12 \cdot 1$ \\
\hline B & $37.8^{b}$ & $0 \cdot 1$ & $15 \cdot 2^{\mathrm{bc}}$ & 0.7 & $12 \cdot 6^{\mathrm{b}}$ & 0.6 & $32.9^{\text {be }}$ & 0.3 & $1 \cdot 21^{\mathrm{bc}}$ & $0 \cdot 17$ & $28 \cdot 5^{b}$ & $3 \cdot 1$ \\
\hline $\mathrm{C}$ & $31 \cdot 8^{\mathrm{c}}$ & 0.5 & $15 \cdot 7^{\mathrm{b}}$ & $0 \cdot 3$ & $11 \cdot 8^{\mathrm{b}}$ & 0.1 & $39 \cdot 1^{\mathrm{c}}$ & 0.4 & $1.46^{\mathrm{bc}}$ & 0.21 & $28 \cdot 1^{b}$ & 3.2 \\
\hline $\mathrm{D}$ & $25 \cdot 9^{\mathrm{d}}$ & 1.5 & $14.9^{b c}$ & 0.5 & $15 \cdot 3^{a}$ & 0.7 & $41 \cdot 6^{c}$ & 1.4 & $1.74^{\mathrm{bc}}$ & 0.31 & $25 \cdot 2^{\mathrm{b}}$ & 2.4 \\
\hline$E$ & $22.6^{\text {de }}$ & 0.8 & $16 \cdot 1^{\mathrm{ab}}$ & 1.5 & $21 \cdot 3^{c}$ & 0.7 & $34 \cdot 0^{\text {be }}$ & 1.6 & $1.55^{\mathrm{b}}$ & 0.10 & $25 \cdot 4^{\mathrm{b}}$ & 3.6 \\
\hline F & $33 \cdot 3^{\mathrm{c}}$ & 0.5 & $14.7^{\mathrm{ab}}$ & 1.0 & $21.9^{\mathrm{c}}$ & 0.7 & $28.8^{\text {ae }}$ & 0.7 & $1.27^{\mathrm{bc}}$ & 0.23 & $25 \cdot 6^{b}$ & 4.0 \\
\hline G & $31 \cdot 5^{\mathrm{c}}$ & 1.0 & $13 \cdot 6^{\mathrm{ac}}$ & 0.6 & $31.0^{\mathrm{d}}$ & 1.0 & $20 \cdot 3^{d}$ & 0.2 & $0.44^{\mathrm{a}}$ & 0.06 & $48 \cdot 7^{\mathrm{a}}$ & 5.9 \\
\hline $\mathrm{H}$ & $21 \cdot 3^{\mathrm{e}}$ & 0.4 & $15 \cdot 6^{\mathrm{bc}}$ & 0.5 & $30 \cdot 4^{\mathrm{d}}$ & 0.2 & $30.9^{\mathrm{c}}$ & 0.3 & $1 \cdot 11^{\mathrm{c}}$ & 0.03 & $27.9^{b}$ & 0.8 \\
\hline I & $21.5^{\mathrm{e}}$ & $1 \cdot 1$ & $12 \cdot 7^{\mathrm{ab}}$ & 2.9 & $44 \cdot 4^{e}$ & 4.0 & $20 \cdot 2^{\mathrm{d}}$ & 0.7 & $0.47^{\mathrm{a}}$ & 0.13 & $50 \cdot 2^{\mathrm{a}}$ & 7.3 \\
\hline
\end{tabular}

PUFA, polyunsaturated fatty acids.

a,b,c,d,e Mean values within a column not sharing a common superscript letter were significantly different $(P<0.05)$.

* For details of diets, see Tables 1 and 2.

\section{Serum and spleen lymphocyte fatty acid composition}

The fatty acid composition of serum is shown in Table 4; only the five most important fatty acids, in terms of their content, are shown. As would be expected the fatty acid composition of serum was strongly affected by that of the diet fed. Serum palmitic acid content was highest in animals fed on $\operatorname{diet} \mathrm{A}$, the diet with the highest palmitic acid content. Conversely serum palmitic acid contents were lowest in animals fed on diets $\mathrm{H}, \mathrm{I}$ and $\mathrm{E}$; these diets contained the lowest levels of palmitic acid. There was a significant $(P<0.0001)$ linear correlation between serum and diet palmitic acid content $(r 0.943)$. Serum oleic acid content was highest in animals fed on diet I, followed by those fed on diets $\mathrm{G}$ and $\mathrm{H}$. These diets contained the highest proportion of oleic acid. There was a significant $(P<0.0001)$ linear correlation between serum and diet oleic acid content $(r$ 0.896). Serum linoleic acid content was highest in animals fed on diets $D$ and $C$, the diets with the highest linoleic acid content. There was a significant $(P<0.0001)$ linear correlation between serum and diet linoleic acid content $(r 0.859)$. There was a significant $(P<0.0001)$ linear correlation between serum and diet $\alpha$-linolenic acid content $(r 0.792)$.

The $n-6: n-3$ PUFA ratio of all diets was maintained at 7 (Table 2). In comparison the $n-6: n-3$ PUFA ratio of total serum lipid was greater than 20 in all animals (Table 4). For animals fed on diets other than A, G or I this ratio was between 25 and 30 (Table 4). However, for animals fed on diets A, G or I this ratio was between 48 and 92 (Table 4). These three diets were those which contained the lowest levels of total PUFA and of $\alpha$ linolenic acid (Table 2). The results suggest that, compared with linoleic acid, $\alpha$-linolenic acid may be relatively poorly absorbed from the diet and/or may be more rapidly cleared from the circulation; furthermore, it appears that if the diet contains low levels of $\alpha$ linolenic acid (e.g. diets A, G or I) then the relative difference between linoleic and $\alpha$ linolenic acids becomes more pronounced.

The fatty acid composition of spleen lymphocytes was determined since there is some evidence that altering the fatty acid composition of lymphocyte phospholipids results in changes in lymphocyte functions (e.g. Calder et al. 1994a; Yaqoob et al. 1995a). Spleen lymphocyte fatty acid composition was affected by diet (Table 5), although not as strongly 


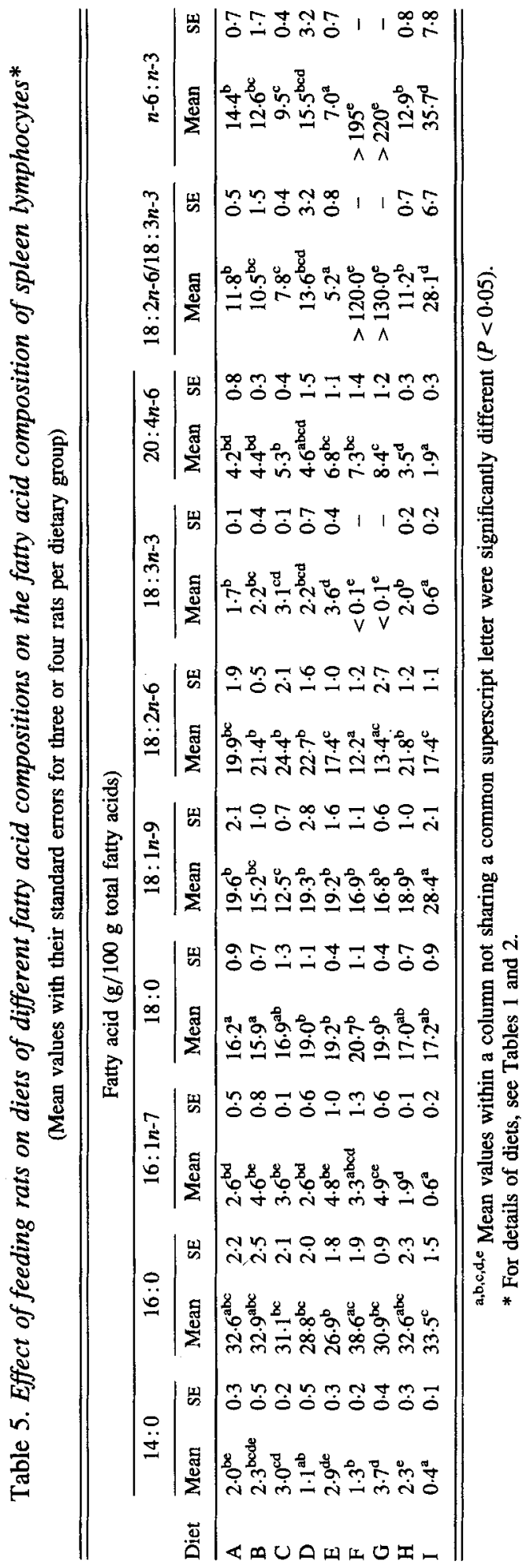


as was that of the serum. A high proportion of palmitic acid (27-39 g/100 $\mathrm{g}$ fatty acids) was present in spleen lymphocytes despite the low levels found in some of the diets. Similarly, the proportion of oleic acid present in spleen lymphocytes varied over a $2 \cdot 2$-fold range (from 12.5 to $28.4 \mathrm{~g} / 100 \mathrm{~g}$ fatty acids), although the proportion in the diet varied over a 3.9-fold range (from 18.5 to $71.6 \mathrm{~g} / 100 \mathrm{~g}$ fatty acids). Spleen lymphocytes from rats fed on diet I had the highest proportion of oleic acid; this diet contained the highest level of oleic acid. The proportion of linoleic acid present in spleen lymphocytes was maintained between 12 and $25 \mathrm{~g} / 100 \mathrm{~g}$ fatty acids while that of arachidonic acid varied between 1.9 and $7.3 \mathrm{~g} / 100 \mathrm{~g}$ fatty acids. There were significant correlations $(P<0.01,0.03$ and 0.002 respectively) between spleen lymphocyte and diet oleic, linoleic and $\alpha$-linolenic acid contents ( $r 0.465,0.378$ and 0.559 , respectively).

The $n-6: n-3$ PUFA ratio of spleen lymphocytes varied widely among animals fed on different diets (Table 5). In most cases this ratio was higher than that of the diet consumed but lower than that of the serum; very high ratios were observed in spleen lymphocytes from animals fed on diets $F$ or $G$ (Table 5). This was largely a result of the very low levels of $\alpha$-linolenic acid which appeared in these cells (Table 5).

\section{Proliferation of spleen lymphocytes}

The proliferation of lymphocytes from the spleens of animals fed on diet D was greater than that of lymphocytes from the spleens of animals fed on diets A, E, H or I (Fig. 2). In addition, the proliferation of spleen lymphocytes from animals fed on diet $\mathrm{C}$ was greater than that of those from animals fed on diets $\mathrm{H}$ or I (Fig. 2).

There were non-significant relationships between the levels of individual fatty acids in the diet and stimulation index (results not shown). This may be because the effect on lymphocyte proliferation of replacing one fatty acid with another was influenced by the level of other fatty acids in the diet. For example, it appeared that there was an increase in

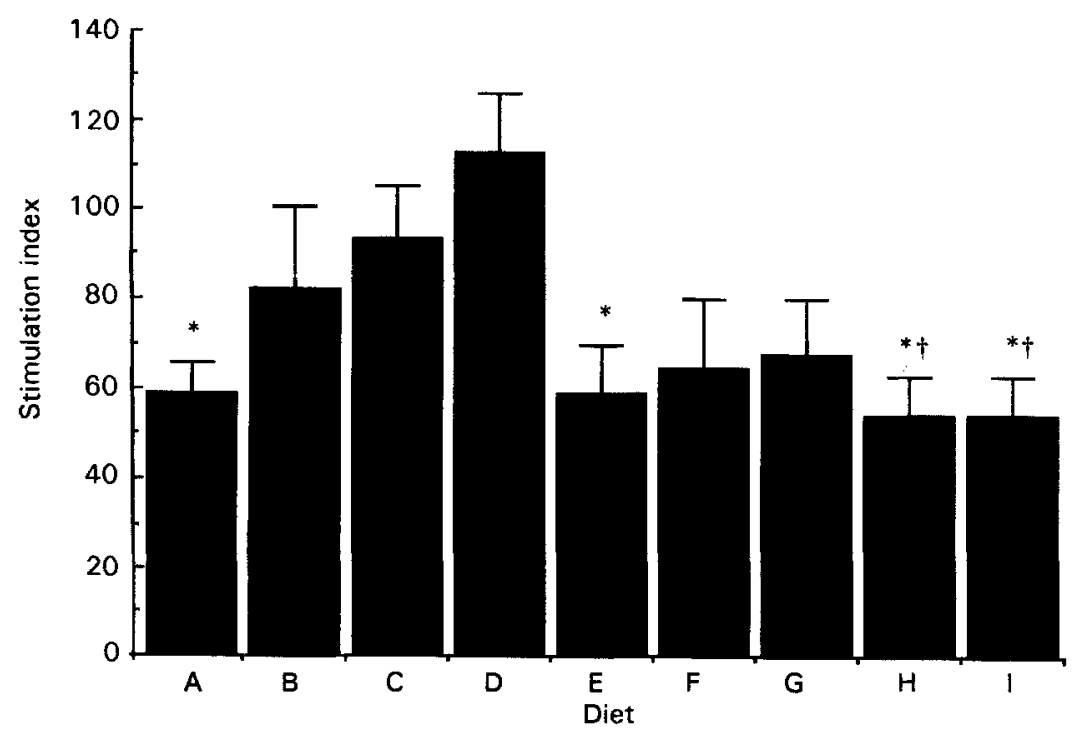

Fig. 2. Effect of feeding rats on diets of different fatty acid compositions on the proliferation of spleen lymphocytes. Values are means with their standard errors from five animals fed on each diet. $*$ Values were significantly different from that for diet $\mathrm{D}, P<0.05$; ${ }^{\dagger}$ Values were significantly different from that for diet $\mathrm{C}, P<0.05$. 
lymphocyte proliferation as the palmitic acid content of the dietary fat increased from 4.5 to $10.3 \mathrm{~g} / 100 \mathrm{~g}$ fatty acids (diets I, H, E and D). However, these diets were characterized by a significant increase in the level of linoleic acid (from 15.4 to $51.7 \mathrm{~g} / 100 \mathrm{~g}$ fatty acids) in exchange for oleic acid which was reduced from 71.6 to $25.2 \mathrm{~g} / 100 \mathrm{~g}$ fatty acids (Table 2). Thus, it is likely that the increase in lymphocyte response seen with these diets was due to the enhancing effect of replacing oleic acid with linoleic acid. As the palmitic acid content of the dietary fat was increased above $10 \mathrm{~g} / 100 \mathrm{~g}$ fatty acids there was a reduction in the lymphocyte proliferative response. Similarly, it appeared that there was a strong enhancement of the lymphocyte proliferative response as the oleic acid content of the dietary fat increased from 18.5 to $25.2 \mathrm{~g} / 100 \mathrm{~g}$ fatty acids (diets A to D). However, diets A to $\mathrm{D}$ were characterized by a large increase in the proportion of linoleic acid (from 15 to $52 \mathrm{~g} / 100 \mathrm{~g}$ total fatty acids) in exchange for palmitic acid which decreased from 57 to $10 \mathrm{~g} / 100 \mathrm{~g}$ fatty acids (Table 2). Thus, the significant increase in lymphocyte proliferation seen with these diets was more probably due to the enhancing effect of replacing palmitic acid with linoleic acid than to the small increase in the level of oleic acid; indeed diets A, B and $\mathrm{C}$ contained almost identical levels of oleic acid (Table 2). Lymphocyte proliferation was decreased at a dietary oleic acid level of $35.6 \mathrm{~g} / 100 \mathrm{~g}$ fatty acids (diet $\mathrm{E}$ ) and increasing the oleic acid level above this did not result in any further decrease. There was a significant inverse linear relationship between stimulation index and the oleic acid : linoleic acid ratio in the diet $(r-0.331 ; P=0.028)$. However, the best-fit relationship between stimulation index and the oleic acid : linoleic acid ratio in the diet was of the form:

$$
\text { stimulation index }=a_{o}+b_{o} \log (\text { oleic acid : linoleic acid }) \text {, }
$$

where $a_{0}=75.8$ and $b_{0}=-18.56(P<0.05$ for both values) (Fig. 3).

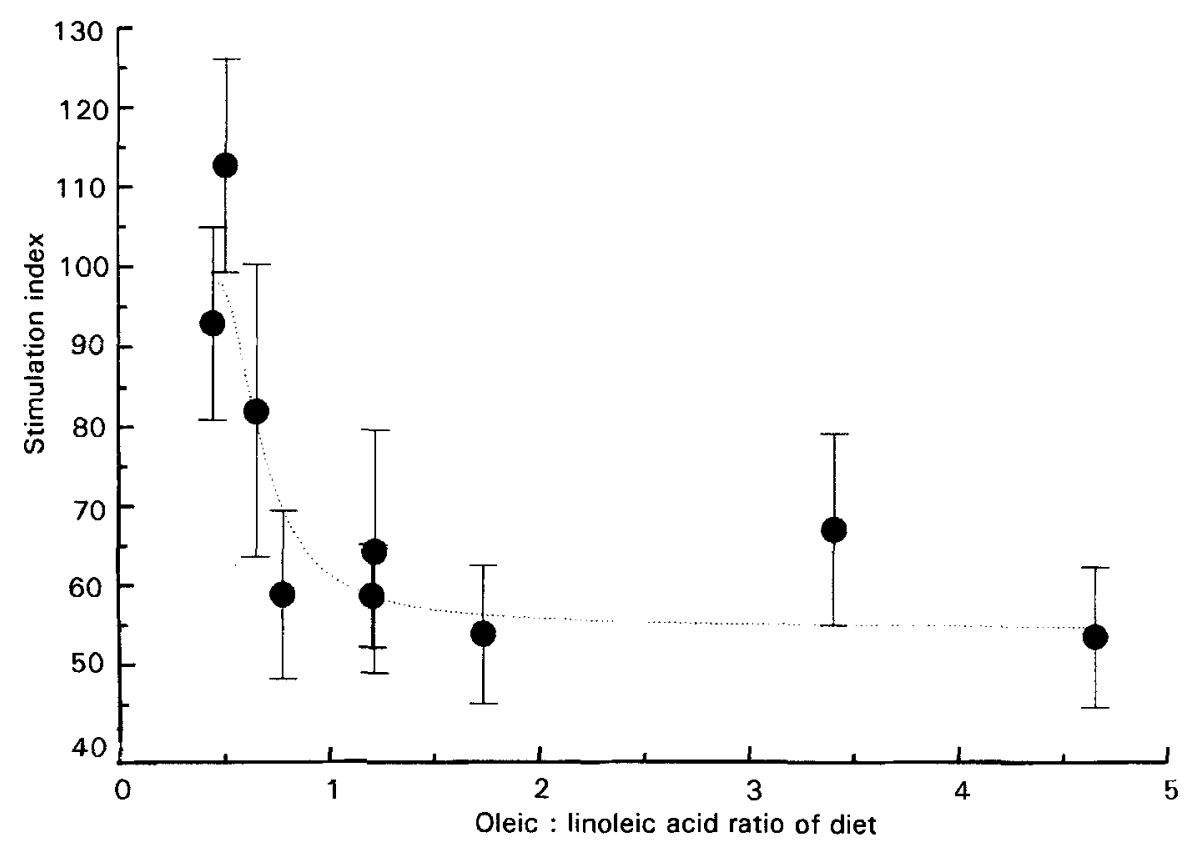

Fig. 3. Relationship between the oleic acid: linoleic acid ratio in the diet and spleen lymphocyte proliferation in rats. Values are means with their standard errors for five rats fed on each diet. 
There were non-significant relationships between the levels of palmitic, oleic, linoleic, $\alpha$-linolenic and arachidonic acids in spleen lymphocytes and the stimulation index of these cells (results not shown). Furthermore, there did not appear to be a relationship between stimulation index and the oleic acid : linoleic acid ratio, the linoleic : $\alpha$-linolenic acid ratio or the $n-6: n-3$ PUFA ratio in the cells (results not shown). These observations suggest that, at least as far as the four fatty acids under study here are concerned, the function of lymphocytes is not closely related to their overall fatty acid composition. However, this does not rule out the possibility that lymphocyte function is influenced by the fatty acid composition of particular phospholipid species; we did not analyse the levels or fatty acid compositions of phospholipid species in the current study.

\section{Spleen natural killer cell activity}

The NK cell activity of spleen lymphocytes was affected by diet (Table 6). This activity was highest following the feeding of diet $\mathrm{A}$ and was significantly diminished by feeding diets $\mathrm{H}$ and $\mathrm{I}$ (Table 6 ). There was a significant positive linear relationship between dietary palmitic acid content and NK cell activity (Table 7), suggesting that dietary palmitic acid causes enhanced NK cell activity. There was a significant negative linear relationship between oleic acid content of the diet and NK cell activity (Table 7; Fig. 4), suggesting that

Table 6. Effect of feeding rats on diets of different fatty acid compositions on spleen lymphocyte natural killer-cell activity*

(Mean values with their standard errors for four rats per dietary group)

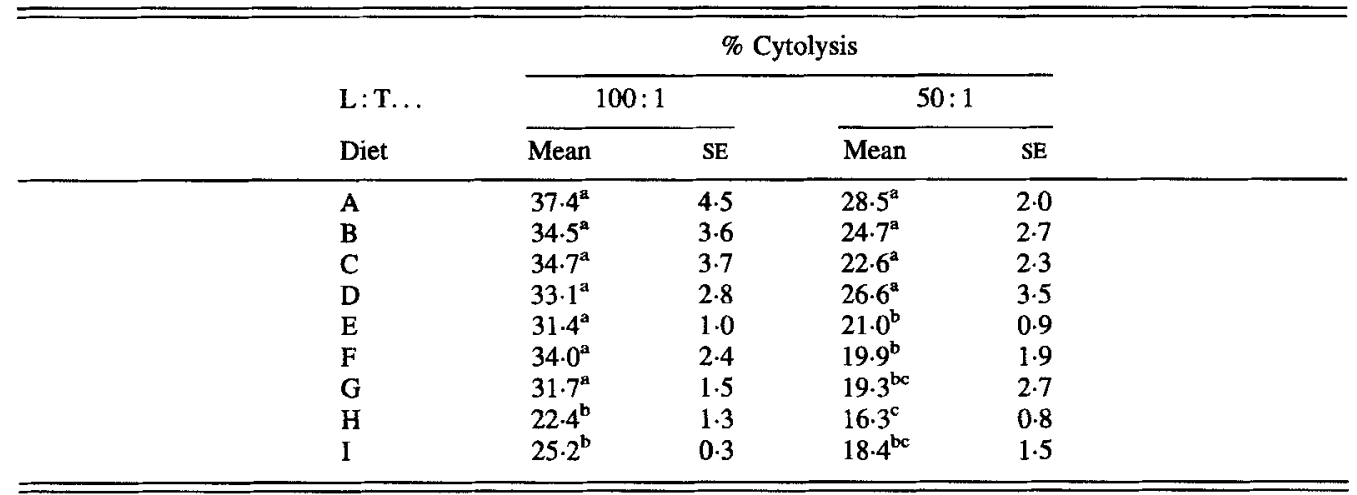

L:T, lymphocyte : target cell ratio.

a,b,c Mean values within a column not sharing a common superscript letter were significantly different $(P<0.05)$.

* For details of diets, see Tables 1 and 2.

Table 7. Spearman linear rank correlation coefficients for the relationships between the levels of individual fatty acids in the diet and spleen natural killer (NK)-cell activity

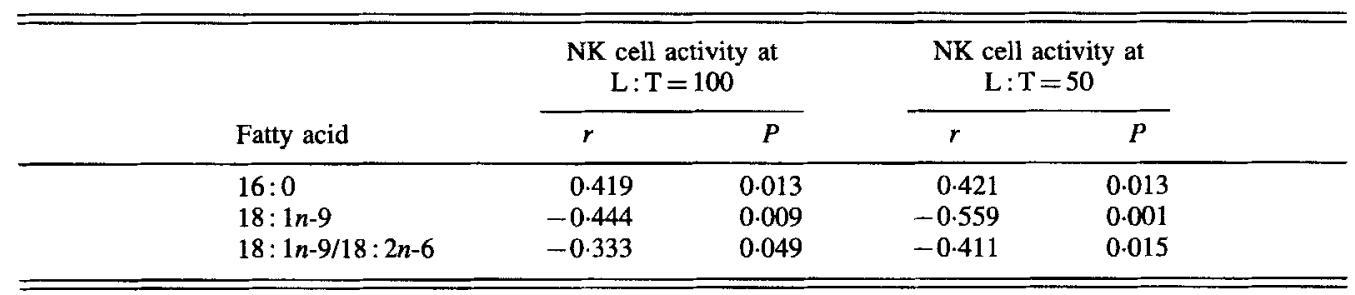




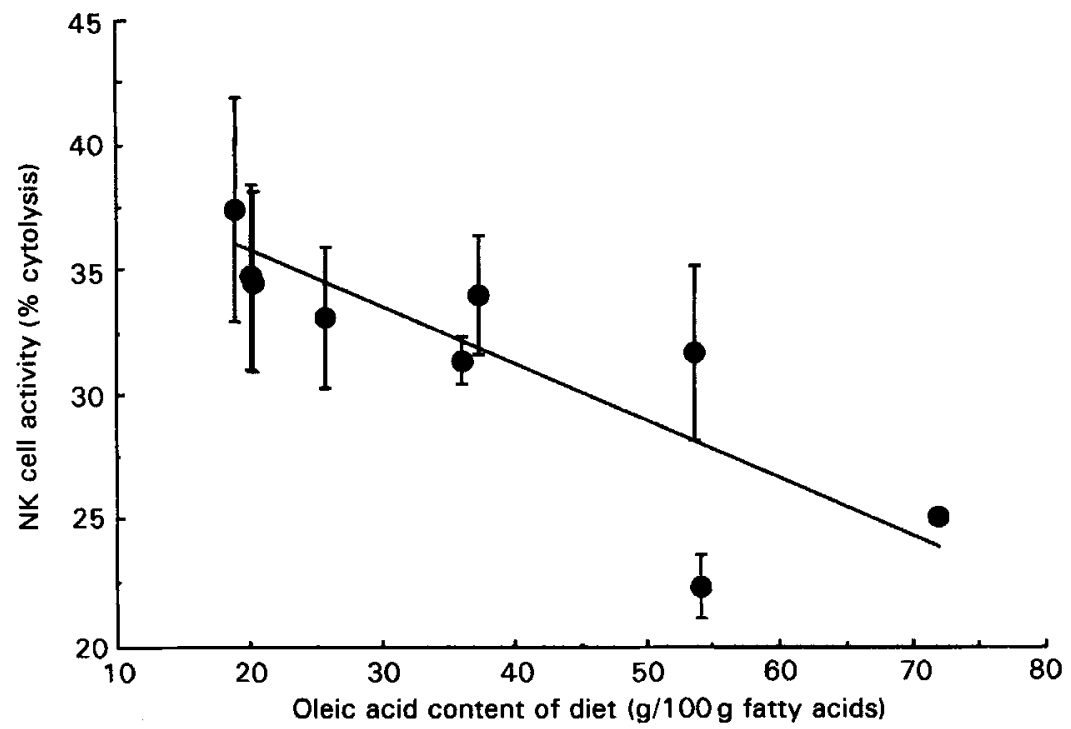

Fig. 4. Relationship between the oleic acid content of the diet and spleen natural killer (NK)-cell activity in rats. Values are means with their standard errors for four rats fed on each diet.

dietary oleic acid causes diminished NK cell activity. Furthermore, there was a negative relationship between the oleic acid:linoleic acid ratio in the diet and NK cell activity (Table 7). There were non-significant correlations between NK cell activity and the linoleic, $\alpha$-linolenic and total PUFA content and the $P: S$ ratio of the diet (results not shown).

There was a weak negative linear relationship $(r-0.289 ; P=0.092)$ between NK cell activity and the level of oleic acid in spleen lymphocytes. There did not appear to be relationships between NK cell activity and the levels of palmitic, linoleic, $\alpha$-linolenic or arachidonic acids in spleen lymphocytes (results not shown), although, once again, the

Table 8. Effect of feeding rats on diets of different fatty acid compositions on spleen lymphocyte subpopulations*

(Mean values with their standard errors for four rats per dietary group)

\begin{tabular}{|c|c|c|c|c|c|c|}
\hline \multirow[b]{3}{*}{ Diet } & \multicolumn{4}{|c|}{ Percentage of positive cells } & & \\
\hline & \multicolumn{2}{|c|}{$\mathrm{CD} 4$} & \multicolumn{2}{|c|}{ CD8 } & \multicolumn{2}{|c|}{$\mathrm{CD} 4: \mathrm{CD} 8$} \\
\hline & Mean & SE & Mean & SE & Mean & SE \\
\hline A & 50.9 & 4.5 & $35 \cdot 7^{\mathrm{a}}$ & 1.9 & $1.6^{\mathrm{ac}}$ & 0.2 \\
\hline $\mathrm{B}$ & 44.9 & $4 \cdot 3$ & $30 \cdot 7^{\text {ad }}$ & 2.6 & $1.7^{\mathrm{ab}}$ & 0.2 \\
\hline C & $45 \cdot 1$ & 3.6 & $26 \cdot 6^{\mathrm{bd}}$ & 1.0 & $1 \cdot 5^{\mathrm{a}}$ & $0 \cdot 1$ \\
\hline $\mathrm{D}$ & $49 \cdot 6$ & 4.0 & $28 \cdot 9^{\text {ad }}$ & $2 \cdot 4$ & $1 \cdot 8^{\mathrm{ab}}$ & 0.3 \\
\hline $\mathrm{E}$ & 51.8 & 2.9 & $26 \cdot 1^{\text {bd }}$ & 1.4 & $1.9^{\mathrm{ab}}$ & 0.2 \\
\hline F & 55.1 & $4 \cdot 1$ & $26 \cdot 1^{\text {bd }}$ & 0.9 & $2 \cdot 3^{\mathrm{b}}$ & 0.2 \\
\hline $\mathrm{G}$ & $57 \cdot 0$ & $4 \cdot 2$ & $32 \cdot 7^{\text {ac }}$ & $2 \cdot 2$ & $2 \cdot 0^{\mathrm{bc}}$ & 0.1 \\
\hline $\mathrm{H}$ & $49 \cdot 3$ & 3.6 & $28 \cdot 5^{\mathrm{cd}}$ & 2.3 & $1.8^{\mathrm{ab}}$ & 0.2 \\
\hline I & 54.7 & $3 \cdot 1$ & $27 \cdot 2^{\text {cd }}$ & 2.5 & $1.8^{\mathrm{ab}}$ & 0.1 \\
\hline
\end{tabular}

a,b,c,d Mean values within a column not sharing a common superscript letter were significantly different $(\boldsymbol{P}<0.05)$.

* For details of diets, see Tables 1 and 2. 
possibility that the fatty acid composition of a particular phospholipid species being important in regulating NK cell function cannot be excluded.

\section{Spleen lymphocyte subsets}

There was no significant effect of diet on the proportion of $\mathrm{CD}^{+}$lymphocytes in the spleen (Table 8). In contrast, there were several significant effects of diet on the proportion of $\mathrm{CD}^{+}$lymphocytes (Table 8). As a result the $\mathrm{CD}^{+}: \mathrm{CD}^{+}$cell ratio was significantly affected by diet, with the lowest values being found in animals fed on diets A, B and C (Table 8).

\section{DISCUSSION}

Many studies have investigated the effects of including high levels of $n-9$ monounsaturated or $n-6$ or $n-3$ PUFA in the diet of laboratory animals on ex vivo lymphocyte functions (see pp. 805-806 for references). These studies show that feeding high levels of $n$-3 PUFA or $n-9$ monounsaturated fatty acids results in markedly diminished lymphocyte proliferation, lymphocyte-mediated cytotoxicity and cell-mediated immunity; diets rich in $n$-6 PUFA are less suppressive (see p. 806). Such studies are useful in establishing the effects of these fatty acids. However, the lipids used differ greatly in their fatty acid compositions, so that the diets being compared often differ in more than simply the fatty acids under scrutiny. Therefore, in order to investigate the effects of different dietary fatty acids on immune cell function we used a series of diets with very similar fatty acid compositions apart from those of the fatty acids under examination. These were palmitic, oleic, linoleic and $\alpha$-linolenic acids; the diets were prepared so that palmitic, oleic and total PUFA were exchanged for one another in a variety of ways (Tables 2 and 3); the $n-6: n-3$ PUFA ratio was maintained at approximately 7 in all diets. The $P: S$ ratio varied from 0.28 to 5.56 (Table 2).

Spleen lymphocyte proliferation in response to the T-cell mitogen Con A was significantly affected by the fatty acid composition of the diet (Fig. 2). The $\mathrm{CD}^{+}: \mathrm{CD}^{+}$ lymphocyte ratio was also affected by diet (Table 8), but there appeared to be no relationship between this ratio and lymphocyte proliferation. We have previously reported that high levels of dietary oleic acid elicit potent suppressive effects on lymphocyte proliferation compared with high levels of linoleic acid (Yaqoob et al. 1994a; Jeffery et al. $1996 \mathrm{~b}$ ). The current study confirms that the level of oleic acid in the diet, particularly in relation to the level of linoleic acid, has a strong effect on spleen lymphocyte proliferation, with moderate-high levels resulting in decreased proliferation compared with lower levels (Fig. 3). In contrast there was no correlation between lymphocyte proliferation and the level of $\alpha$-linolenic acid in the diet. This finding may appear surprising in the light of previous studies which have shown suppression of lymphocyte proliferation after feeding rats diets rich in linseed oil (Marshall \& Johnston, 1985; Jeffery et al. 1996a). However, linseed oil contains $50-60 \mathrm{~g} \alpha$-linolenic acid/100 $\mathrm{g}$ fatty acids and has a very low $n-6: n-3$ PUFA ratio (approximately 0.3). The level of $\alpha$-linolenic acid used in the current study never exceeded $6.8 \mathrm{~g} / 100 \mathrm{~g}$ fatty acids (Table 2 ). This was clearly an insufficient level of $\alpha$ linolenic acid for it to exert any suppressive effect.

We have previously found that spleen lymphocytes from animals fed on a diet containing $200 \mathrm{~g}$ olive oil $/ \mathrm{kg}$ proliferate approximately half as well as those from animals fed on a diet containing $200 \mathrm{~g}$ safflowerseed oil $/ \mathrm{kg}$ (Jeffery et al. 1996b). In the current study the fatty acid composition of diets I and D closely resembled those of the olive and safflowerseed oil diets. In agreement with our observations with the latter diets 
lymphocytes from rats fed diet I proliferated approximately half as well as those from rats fed on diet D (Fig. 2).

Spleen NK cell activity was significantly affected by the fatty acid composition of the diet (Table 6). We have previously observed that high levels of dietary oleic (Yaqoob et al. 1994b; Jeffery et al. 1996b) and $\alpha$-linolenic (Jeffery et al. 1996a) acids elicit potent suppressive effects on NK cell activity and that this activity is enhanced if animals are fed on diets rich in palmitic acid at the expense of other saturated fatty acids (Jeffery et al. 1997). The current study found that there was a significant negative correlation between the oleic acid content of the diet and spleen NK cell activity (Table 7; Fig. 4) and a significant positive correlation between the palmitic acid content of the diet and spleen NK cell activity (Table 7). Spleen NK cell activity was not influenced by the level of $\alpha$-linolenic acid in the diet; again this is most probably due to the much lower level of $\alpha$-linolenic acid used in the current study. The difference in NK cell activity between animals fed on diets I and D (Table 6) was similar to that which has been reported previously for animals fed on diets rich in olive or safflowerseed oils (Yaqoob et al. 1994b; Jeffery et al. 1996b).

The design of the diets used in the present study allows a detailed examination, for the first time, of the interaction of dietary fatty acids with respect to their immunomodulatory actions. The comparisons being made are summarized in Table 3. These comparisons indicate that simply exchanging one fatty acid for another does not always have the same effect; the level of the background fatty acid in the diet is also important. For example, replacing palmitic acid with PUFA resulted in enhanced lymphocyte proliferation if the diet contained a low level of oleic acid (diets A, B, C and D), indicating that linoleic acid increases proliferation compared with palmitic acid (at least in the presence of low levels of oleic acid). However, if the diet contained moderate or high levels of oleic acid (diets $F$ and $\mathrm{E}$ or $\mathrm{G}$ and $\mathrm{H}$ ) replacing palmitic acid with PUFA had little effect on proliferation (Fig. 2), indicating that oleic acid can overcome the enhancing effect of PUFA if it is present at a sufficient level.

If dietary palmitic acid was replaced by oleic acid, NK cell activity decreased whatever the level of PUFA in the diet (diets A, G and I or B, F and H or C, D and E; Table 6). Furthermore, if dietary PUFA were replaced by oleic acid there was a decrease in NK cell activity, whatever the level of palmitic acid in the diet (diets D, E, H and I or C, F and G). These observations indicate that oleic acid decreases NK cell activity compared with both palmitic acid and PUFA.

Several linear and non-linear models were used to investigate interactions between the levels of the different fatty acids in the diet and their effects on lymphocyte proliferation and NK cell activity; however, none of these models revealed a significant interaction between the four fatty acids under study.

Thus, the present study confirms that lymphocyte functions are influenced by dietary fatty acids. It shows that effects on lymphocyte functions are not restricted to the feeding of diets with extreme fatty acid compositions (e.g. fish oil, linseed oil) but occur as a function of the dietary level of the commonly consumed fatty acids (palmitic, oleic, linoleic) in the diet. This study confirms that dietary oleic acid has a significant suppressive effect on spleen lymphocyte proliferation and NK cell activity and that this effect is dose-dependent. Furthermore this study confirms our recent observation (Jeffery et al. 1997) that dietary palmitic acid enhances NK cell activity; again this effect is dose-dependent. Where this study deviates from those performed previously is in the observations that dietary $\alpha$ linolenic acid was largely without effect on lymphocyte functions; however this is most probably due to the much lower levels of this fatty acid used in the current study. It seems that a linseed oil-rich diet contains $\alpha$-linolenic acid at levels far in excess of those which 
result in optimal lymphocyte function. It is often assumed that dietary PUFA per se are immunosuppressive. This study shows that this is not the case: lymphocyte proliferation and NK cell activity were not strongly related to the level of either linoleic acid or total PUFA in the diet. It is apparent that the exact effect of any given fatty acid not only depends on how much of that fatty acid there is in the diet, but also on the amount relative to that of other fatty acids.

There were no clear relationships between the proportions of individual fatty acids in spleen lymphocytes and the function of those cells. As indicated on p. 815, this may be because the fatty acid composition data were obtained from whole cells and it is possible that the fatty acid composition of a particular phospholipid species is important in regulating lymphocyte function. Furthermore, the fatty acid composition data are for the mixture of spleen lymphocytes which includes several classes of T lymphocytes as well as B lymphocytes, macrophages and NK cells. It is possible that each cell type undergoes slightly different changes in fatty acid composition following manipulation of the fatty acid composition of the diet. NK cells, whose function was assessed in the current study, comprise less than $10 \%$ of spleen lymphocytes and, thus, important changes in the fatty acid composition of this class of cells could have been undetected when the composition of the entire lymphocyte population was analysed. There is evidence that different lymphocyte populations undergo different changes in fatty acid composition in response to dietary lipid manipulation. For example, Tiwari et al. (1987) reported that the fatty acid compositions of the phospholipids of murine spleen $\mathrm{T}$ and $\mathrm{B}$ lymphocytes were affected differently following the feeding of a diet which contained a high proportion of linoleic acid. Differential effects of dietary supplementation with $n-3$ PUFA on the fatty acid composition of subsets of human peripheral blood mononuclear cells have also been reported (Gibney \& Hunter, 1993). It is also worth noting that the degree of change in fatty acid composition which lymphocytes undergo in response to dietary changes appears to be related to their tissue of origin (Yaqoob et al. 1995a).

The lymphocytes which had lowest NK cell activity were those from animals fed on diets $\mathrm{H}$ or I; at the lymphocyte : target cell ratio of 100:1 the NK cell activity of these lymphocytes was significantly lower than that of lymphocytes from animals fed on each of the other diets (Table 7). Spleen lymphocytes from animals fed on diets $\mathrm{H}$ and $\mathrm{I}$ also contained the lowest proportions of arachidonic acid; that of lymphocytes from rats fed on diet I was less than the proportion found in lymphocytes from rats fed on each of the other diets (Table 5). The arachidonic acid-derived mediator leukotriene $B_{4}$ is a potent enhancer of NK cell activity (Rola-Pleszczynski et al. 1983). Therefore the lower NK cell activity observed after feeding diets $\mathbf{H}$ or I may be due to diminished production of this mediator because of the smaller amount of precursor fatty acid (i.e. arachidonic acid) available. The effects of diet on lymphocyte proliferation cannot be explained by such a mechanism however. Lymphocytes from animals fed on diets $A$ and $E$ to I all proliferated to the same extent (Fig. 2) yet they contained proportions of arachidonic acid varying between 1.9 and $8.4 \mathrm{~g} / 100 \mathrm{~g}$ fatty acids (Table 5), while lymphocytes from animals fed on diet $\mathrm{D}$ had the highest stimulation index (Fig. 2) and these lymphocytes contained $4.6 \mathrm{~g}$ arachidonic acid $/ 100 \mathrm{~g}$ fatty acids (Table 5). Therefore, it seems likely that a mechanism independent of arachidonic acid levels and of the production of arachidonic acid-derived mediators must be involved in causing the differences in lymphocyte proliferation observed. Interestingly, the lymphocytes which proliferated to the greatest extent (those from animals fed on diets D, C or B; Fig. 2) were those which had the highest total PUFA content (28$33 \mathrm{~g} / 100 \mathrm{~g}$ fatty acids compared with $19-28 \mathrm{~g} / 100 \mathrm{~g}$ fatty acids for the other lymphocyte preparations; Table 5). Thus, the diet-induced effect on lymphocyte proliferation may 
relate in some way to the physical nature of the plasma membrane which will be affected by the proportion of PUFA it contains.

The interaction of T-lymphocytes with antigens or, as in this study, mitogens results in activation of a number of signal transduction pathways. These include the pathway involving phospholipase $\mathrm{C}$ which results in cleavage of phosphatidylinositol-4,5-bisphosphate $\left(\mathrm{PIP}_{2}\right)$ to yield the second messengers diacylglycerol (DAG) and inositol-1,4,5trisphosphate $\left(\mathrm{IP}_{3}\right)$; DAG in turn activates protein kinase $\mathrm{C}$ while $\mathrm{IP}_{3}$ induces a rise in the concentration of cytosolic free $\mathrm{Ca}$. At the same time, and depending on the exact nature of the stimulus received by the cells, other membrane phospholipids (e.g. phosphatidylcholine (PC), sphingomyelin) and enzymes (e.g. phospholipase D (EC 3.1.4.4), sphingomyelinase (EC 3.1.4.12)) will be involved in the formation of other second-messengers (e.g. DAG, ceramide). In these ways a variety of intracellular signalling mechanisms become operative and act to bring about the overall cell functional response. There is some evidence that changing the fatty acid compositions of $\mathrm{PC}$ and $\mathrm{PIP}_{2}$ affects their abilities to act as substrates for phospholipases $\mathrm{D}$ and $\mathrm{C}$ respectively, and so alters the activity of the signal transduction pathways (Fowler et al. 1993). Thus, changing the fatty acid composition of specific phospholipid classes might have a profound effect on lymphocyte function.

The proliferative response of lymphocytes to mitogenic stimulation and the interaction of NK cells with their targets involves proteins such as adhesion molecules on the surface of the lymphocytes. These proteins interact with their ligands on the surface of other cells to ensure an efficient functional response. The expression of adhesion molecules on the surface of lymphocytes was not examined in the present study. However, there is evidence from other studies that increasing the amount of oleic acid consumed in the diet decreases the expression of these important molecules on the surface of lymphocytes from rat spleen and lymph nodes (Sanderson et al. 1995a, b) and from human peripheral blood (P. Yaqoob, J. Knapper, D. Webb, E. A. Newsholme, C. M. Williams \& P. C. Calder, unpublished results). If such an effect occurred in the current study this could explain the decrease in lymphocyte proliferation and NK cell activity in response to an increase in the amount of oleic acid in the diet (Figs. 3 and 4). A particular fatty acid could affect adhesion molecule expression either by effects on the membrane environment of the protein or by an effect on its synthesis.

There are a number of diseases in man associated with an inappropriately-active immune system; these include ulcerative colitis, rheumatoid arthritis, psoriasis and lupus. Often these diseases are characterized by the presence of activated lymphocytes and their products at the site of tissue damage. There have been many studies aimed at relieving the biochemical, immunological and clinical symptoms of these diseases by the use of dietary lipids. Many of these studies have shown some benefit from the use of fish oil supplements (see pp. 805-806). The results of the current study suggest that an increased intake of oleic acid, particularly in combination with a decrease in the intake of linoleic acid, might also be of benefit in such diseases. There is some support for this suggestion: Linos et al. (1991) reported an inverse relationship between olive oil consumption and the incidence of rheumatoid arthritis in a Greek population, while some studies which used olive oil as a placebo for studies investigating the effect of fish oil in inflammatory diseases found that the beneficial effects of olive oil were often as potent as those of fish oil (e.g. Cleland $e t$ al. 1988; Kremer et al. 1990). Thus, it seems that increased consumption of oleic acid-rich oils might afford protection against the development of inflammatory diseases and could be used as therapy in such diseases. On the other hand the results of the current study indicate that increasing the level of linoleic acid in the diet, particularly at the expense of oleic acid, 
might enhance lymphocyte reactivity. This may make individuals more susceptible to inflammatory diseases. Hodge et al. (1994) have proposed that the increase in the incidence of asthma in Australia is related to the increased consumption of linoleic acid-based products while recently Shoda et al. (1996) reported that the increase in ulcerative colitis in Japan is related to the increased intake of linoleic acid. It was suggested that the increased incidence of these diseases is due to the increased ability to produce arachidonic acidderived mediators. Both these reports suggested that the dietary imbalance could be improved by increasing the consumption of $n-3$ PUFA; increasing the consumption of oleic acid might also play a beneficial role. However, the current study also indicates that the nature of the background diet will very much alter the effectiveness of dietary supplementation and of small dietary manipulations. This may be partly responsible for the variations which are observed in response to dietary supplementation in man and it may have a considerable impact on the outcome of trials of such supplementation in both healthy volunteers and patient groups.

This research is supported by Unilever Research Laboratories and the Ministry of Agriculture, Fisheries and Food under the Agro-Food Quality LINK Programme (LINK AFQ51).

\section{REFERENCES}

Bates, D., Cartlidge, N. E. F., French, J. M., Jackson, M. J., Nightingale, S., Shaw, D. A., Smith, S., Woo, E., Hawkins, S. A., Millar, J. H. D., Belin, J., Conroy, D. M., Gill, S. K., Sidey, M., Smith, A. D., Thompson, R. H. S., Zilkha, K., Gale, M. \& Sinclair, H. M. (1989). A double-blind controlled trial of long chain $n-3$ polyunsaturated fatty acids in the treatment of multiple sclerosis. Journal of Neurology, Neurosurgery and Psychiatry 52, 18-22.

Berger, A., German, J. B., Chiang, B. L., Ansari, A. A., Keen, C. L., Fletcher, M. P. \& Gershwin, M. R. (1993). Influence of feeding unsaturated fats on growth and immune status of mice. Journal of Nutrition 123, 225233.

Bittiner, S. B., Tucker, W. F. G., Cartwright, I. \& Bleehen, S. S. (1988). A double-blind, randomised, placebocontrolled trial of fish oil in psoriasis. Lancet $\mathrm{i}, 378-380$.

Calder, P. C. (1995). Fatty acids, dietary lipids and lymphocyte functions. Biochemical Society Transactions 23, 302-309.

Calder, P. C. (1996a). Effects of fatty acids and dietary lipids on cells of the immune system. Proceedings of the Nutrition Society 55, 127-150.

Calder, P. C. (1996b). Immunomodulatory and anti-inflammatory effects of $n-3$ polyunsaturated fatty acids. Proceedings of the Nutrition Society 55, 737-774.

Calder, P. C., Bevan, S. J. \& Newsholme, E. A. (1992). The inhibition of T-lymphocyte proliferation by fatty acids is via an eicosanoid-independent mechanism. Immunology 75, 108-115.

Calder, P. C., Bond, J. A., Bevan, S. J., Hunt, S. V. \& Newsholme, E. A. (1991). Effect of fatty acids on the proliferation of concanavalin A-stimulated rat lymph node lymphocytes. International Journal of Biochemistry 23, 579-588.

Calder, P. C., Costa-Rosa, L. F. B. P. \& Curi, R. (1995). Effects of feeding lipids of different fatty acid compositions upon rat lymphocyte proliferation. Life Sciences 56, 455-463.

Calder, P. C. \& Newsholme, E. A. (1992a). Unsaturated fatty acids suppress interleukin-2 production and transferrin receptor expression by concanavalin A-stimulated rat lymphocytes. Mediators of Inflammation 1, 107-115.

Calder, P. C. \& Newsholme, E. A. (1992b). Polyunsaturated fatty acids suppress human peripheral blood lymphocyte proliferation and interleukin-2 production. Clinical Science 82, 695-700.

Calder, P. C., Yaqoob, P., Harvey, D. J., Watts, A. \& Newsholme, E. A. (1994a). The incorporation of fatty acids by lymphocytes and the effect on fatty acid composition and membrane fluidity. Biochemical Journal 300, 509-518.

Calder, P. C., Yaqoob, P. \& Newsholme, E. A. (1994b). Triacylglycerol metabolism by lymphocytes and the effect of triacylglycerols upon lymphocyte proliferation. Biochemical Journal 298, 605-611.

Cleland, L. G., French, J. K., Betts, W. H., Murphy, G. A. \& Elliott, M. J. (1988). Clinical and biochemical effects of dietary fish oil supplements in rheumatoid arthritis. Journal of Rheumatology 15, 1471-1475. 
Das, U. N. (1994). Beneficial effect of eicosapentaenoic and docosahexaenoic acids in the management of systemic lupus erythematosus and its relationship to the cytokine network. Prostaglandins, Leukotrienes and Essential Fatty Acids 51, 207-213.

Erickson, K. L. (1984). Dietary fat influences on murine melanoma growth and lymphocyte-mediated cytotoxicity. Joumal of the National Cancer Institute 72, 115-120.

Fowler, K. H., McMurray, D. N., Fan, Y.-Y., Aukema, H. M. \& Chapkin, R. S. (1993). Purified dietary n-3 polyunsaturated fatty acids alter diacylglycerol mass and molecular species composition in concanavalin Astimulated murine splenocytes. Biochimica et Biophysica Acta 1210, 89-96.

Fritsche, K. L. \& Cassity, N. A. (1992) Dietary $n-3$ fatty acids reduce antibody-dependent cell cytotoxicity and alter eicosanoid release by chicken immune cells. Poultry Science 71, 1646-1657.

Fritsche, K. L., Cassity, N. A. \& Huang, S.-C. (1991). Effect of dietary fat source on antibody production and lymphocyte proliferation in chickens. Poultry Science 70, 611-617.

Fritsche, K. L. \& Johnston, P. V. (1989). Modulation of eicosanoid production and cell-mediated cytotoxicity by dietary $\alpha$-linolenic acid in BALB/c mice. Lipids 24, 305-311.

Fritsche, K. L. \& Johnstone, P. V. (1990). Effect of dietary omega-3 fatty acids on cell-mediated cytotoxicity in BALB/c mice. Nutrition Research 10, 577-588.

Fujikawa, M., Yamashita, N., Yamazaki, K., Sugiyama, E., Suzuki, H. \& Hamazaki, T. (1992). Eicosapentaenoic acid inhibits antigen-presenting cell function of murine splenocytes. Immunology 75 , 330-335.

Gallai, V., Sarchielli, P., Trequattrini, A., Franceschini, M., Floridi, A., Firenze, C., Alberti, A., Di Benedetto, D. \& Stragliotto, E. (1993). Cytokine secretion and eicosanoid production in the peripheral blood mononuclear cells of MS patients undergoing dietary supplementation with $n-3$ polyunsaturated fatty acids. Journal of Neuroimmunology 56, 143-153.

Gibney, M. J. \& Hunter, B. (1993). The effects of short- and long-term supplementation with fish oil on the incorporation of $n-3$ polyunsaturated fatty acids into cells of the immune system in healthy volunteers. European Journal of Clinical Nutrition 47, 255-259.

Grimminger, F., Fuhrer, D., Papavassilis, C., Schlotzer, E., Mayer, K., Heuer, K.-U., Kiss, L., Walmrath, D., Piberhofer, S., Lubbecke, F., Kramer, H.-J., Stevens, J., Schutterle, G. \& Seeger, W. (1993). Influence of intravenous $n$-3 lipid supplementation on fatty acid profiles and lipid mediator generation in a patient with severe ulcerative colitis. European Journal of Clinical Investigation 23, 706-715.

Hinds, A. \& Sanders, T. A. B. (1993). The effect of increasing levels of dietary fish oil rich in eicosapentaenoic and docosahexaenoic acids on lymphocyte phospholipid fatty acid composition and cell-mediated immunity in the mouse. British Journal of Nutrition 69, 423-429.

Hodge, L., Peat, J. K. \& Salome, C. (1994). Increased consumption of polyunsaturated oils may be a cause of increased prevalence of childhood asthma. Australian and New Zealand Journal of Medicine 24, 727.

Homan van der Heide, J. J., Bilo, H. J. G., Donker, J. M., Wilmink, J. M. \& Tegzess, A. M. (1993). Effect of dietary fish oil on renal function and rejection in cyclosporine-treated recipients of renal transplants. New England Journal of Medicine 329, 769-773.

Jeffery, N. M., Sanderson, P., Newsholme, E. A. \& Calder, P. C. (1997). Effects of varying the type of saturated fatty acid in the rat diet upon serum lipid levels and spleen lymphocyte functions. Biochimica et Biophysica Acta (In the Press).

Jeffery, N. M., Sanderson, P., Sherrington, E. J., Newsholme, E. A. \& Calder, P. C. (1996a). The ratio of $n-6$ to $n-3$ polyunsaturated fatty acids in the rat diet alters serum lipid levels and lymphocyte functions. Lipids 31, 737-745.

Jeffery, N. M., Yaqoob, P., Newsholme, E. A. \& Calder, P. C. (1996b). The effects of olive oil upon rat serum lipid levels and lymphocyte functions appear to be due to oleic acid. Annals of Nutrition and Metabolism 40 , $71-80$.

Kelley, D. S., Nelson, G. J., Serrato, C. M., Schmidt, P. C. \& Branch, L. B. (1988). Effects of type of dietary fat on indices of immune status of rabbits. Journal of Nutrition 118, 1376-1384.

Kremer, J. M., Lawrence, D. A., Jubiz, W., Di Giacomo, R., Rynes, K., Bartholomew, L. E. \& Sherman, M. (1990). Dietary fish oil and olive oil supplementation in patients with rheumatoid arthritis. Arthritis and Rheumatism 33, 810-820.

Kromann, N. \& Green, A. (1980). Epidemiological studies in the Upernavik District, Greenland. Acta Medica Scandinavica 208, 401-406.

Kumar, G. S., Das, U. N., Kumar, K. V., Madhavi, N., Das, N. P. \& Tan, B. K. H. (1992). Effect of $n-6$ and $n-3$ fatty acids on the proliferation of human lymphocytes and their secretion of TNF- $\alpha$ and IL-2 in vitro. Nutrition Research 12, 815-823.

Linos, A., Kaklamanis, E., Kontomerkos, A., Koumantaki, Y., Gazi, S., Vaiopoulos, G., Tsokos, G.C. \& Kaklamanis, P. (1991). The effect of olive oil and fish consumption on rheumatoid arthritis - A case control study. Scandinavian Journal of Rheumatology 20, 419-426.

Marshall, L. A. \& Johnston, P. V. (1985) The influence of dietary essential fatty acids on rat immunocompetent cell prostaglandin synthesis and mitogen-induced blastogenesis. Journal of Nutrition 115, 1572-1580. 
Mertin, J. \& Hunt, R. (1976). Influence of polyunsaturated fatty acids on survival of skin allografts and tumor incidence in mice. Proceedings of the National Academy of Science USA 73, 928-931.

Mertin, J., Hughes, D. \& Stewart-Wynne, E. (1974). PHA transformation in MS: inhibition by linoleic acid. Lancet i, 1005-1006.

Mertin, J. \& Meade, C. J. (1977) Relevance of fatty acids to multiple sclerosis. British Medical Bulletin 33, 6771.

Mertin, J., Stackpole, A. \& Shumway, S. (1985). Nutrition and immunity: the immunoregulatory effect of $n-6$ essential fatty acids is mediated through prostaglandin E. International Archives of Allergy and Applied Immunology 77, 390-395.

Meydani, S. N., Yogeeswaran, G., Liu, S., Baskar, S. \& Meydani, M. (1988). Fish oil and tocopherol-induced changes in natural killer cell-mediated cytotoxicity and $\mathrm{PGE}_{2}$ synthesis in young and old mice. Journal of Nutrition 118, 1245-1252.

Olson, L. M., Clinton, S. K., Everitt, J. I., Johnston, P. V. \& Visek, W. J. (1987). Lymphocyte activation, cellmediated cytotoxicity and their relationship to dietary fat-enhanced mammary tumorigenesis in C3H/OUJ mice. Journal of Nutrition 117, 955-963.

Rola-Pleszczynski, M., Gagnon, L. \& Sirois, P. (1983). Leukotriene B4 augments human natural cytotoxic cell activity. Biochemical and Biophysical Research Communications 113, 531-537.

Sanderson, P., Yaqoob, P. \& Calder, P. C. (1995a) Effects of dietary lipid manipulation upon graft vs. host and host vs. graft responses in the rat. Cellular Immunology 164, 240-247.

Sanderson, P., Yaqoob, P. \& Calder, P. C. (1995b). Effects of dietary lipid manipulation upon rat spleen lymphocyte functions and the expression of lymphocyte surface molecules. Journal of Nutritional and Environmental Medicine 5, 119-132.

Sherrington, E. J., Yaqoob, P. \& Calder, P. C. (1994). Differential effects of high fat diets on adipose tissue deposition in the rat. Proceedings of the Nutrition Society 53, 69A.

Shoda, R., Matsueda, K., Yamato, S. \& Umeda, N. (1996). Epidemiologic analysis of Crohn disease in Japan: increased dietary intake of $n-6$ polyunsaturated fatty acids and animal protein relates to the increased incidence of Crohn disease in Japan. American Journal of Clinical Nutrition 63, 741-745.

Soyland, E., Nenseter, M. S., Braathen, L. \& Drevon, C. A. (1993) Very long chain $n-3$ and $n-6$ polyunsaturated fatty acids inhibit proliferation of human T-lymphocytes in vitro. European Journal of Clinical Investigation 23, $112-121$.

Sperling, R. I., Weinblatt, M. E., Robin, J. L., Ravalese, J., Hoover, R. L., House, F., Coblyn, J. S., Fraser, P. A., Spur, B. W., Robinson, D. R., Lewis, R. A. \& Austen, K. F. (1987). Effects of dietary supplementation with marine fish oil on leukocyte lipid mediator generation and function in rheumatoid arthritis. Arthritis and Rheumatism 30, 987-988.

Swank, R. L. (1950). Multiple sclerosis: a correlation of its incidence with dietary fat. American Journal of Medical Science 220, 421-430.

Tiwari, R. K., Clandinin, M. T., Cinader, B. \& Goh, Y. K. (1987). Effect of high polyunsaturated fat diets on the composition of B cell and T cell membrane lipids. Nutrition Research 7, 489-498.

Yamashita, N., Maruyama, M., Yamazaki, K., Hamazaki, T. \& Yano, S. (1991). Effect of eicosapentaenoic and docosahexaenoic acid on natural killer cell activity in human peripheral blood lymphocytes. Clinical Immunology and Immunopathology 59, 335-345.

Yaqoob, P. \& Calder, P. C. (1995). The effects of dietary lipid manipulation on the production of murine T-cellderived cytokines. Cytokine 7, 548-553.

Yaqoob, P., Newsholme, E. A. \& Calder, P. C. (1994a). The effect of dietary lipid manipulation on rat lymphocyte subsets and proliferation. Immunology 82, 603-610.

Yaqoob, P., Newsholme, E. A. \& Calder, P. C. (1994b). Inhibition of natural killer cell activity by dietary lipids. Immunology Letters 41, 241-247.

Yaqoob, P., Newsholme, E. A. \& Calder, P. C. (1995a). Influence of cell culture conditions on diet-induced changes in lymphocyte fatty acid composition. Biochimica et Biophysica Acta 1255, 333-340.

Yaqoob, P., Sherrington, E. J., Jeffery, N. M., Sanderson, P., Harvey, D. J., Newsholme, E. A. \& Calder, P. C. $(1995 \mathrm{~b})$. Comparison of the effects of a range of dietary lipids upon serum and tissue lipid composition in the rat. International Journal of Biochemistry and Cell Biology 27, 297-310.

Ziboh, V. A., Cohen, K. A., Ellis, C. N., Miller, C., Hamilton, T. A., Kragballe, K., Hydrick, C. R. \& Voorhees, J. J. (1986). Effects of dietary supplementation of fish oil on neutrophil and epidermal fatty acids: modulation of clinical course of psoriatic lesions. Archives of Dermatology 122, 1277-1282. 